\title{
Reinga to Leina: Ghost - Dancing Leylines
}

Ko Hikurangi raua ko Tarakeha nga maunga

Ko Waiapu raua ko Moetangi nga awa

Ko Tuatini raua ko Matihetihe nga marae

Ko Te Whanau a Ruataupare raua ko Hokokeha nga hapu

Ko Ngati Porou raua ko Te Rarawa nga iwi

\section{Abstract}

In this essay I evoke ghostly remnants of my choreographic research practices ${ }^{1}$ facilitated via a series of global interdisciplinary collaborations in Hawaii $^{2}$ and California ${ }^{3}$ bridging Māori cosmologies and epistemological frame works with intercultural collectives ${ }^{4}$. Reconstructing diary, email and interview

1 Cultural interventions within community spaces of exchange such as public singing lessons, group visits to sites, performative explorations, community sleepovers.

2 Work was undertaken at The Bernice Pauahi Bishop Museum during a seven week artist residency in 2013

3 Work was undertaken as a guest choreographer in residence at University of California Berkeley for the Berkeley Dance Project in 2014 and as an Assistant Professor at the University of California Riverside during Spring Quarter 2014

$4 \quad$ I am a founding member of Atamira Dance Company and was involved in the collaboration of the Whare Tapere by Charles Royal and Louise Potiki Bryant 
material ${ }^{5}$ offers a unique creative insight into contemporary Maori performing art practices, re-experiencing the presentness of time, as intimately informed by an erased other, where the former recipient now becomes the medium, the ghost reader. This essay mirrors the creative processes, tracing moments, already lived, to dance the intangible spirit across leylines of transitional space ${ }^{6}$.

\section{Hawaii}

In 2013, I facilitated 'Te Reinga' a cross cultural performance collaboration at the Bernice Pauahi Bishop Museum in Honolulu, Hawaii ${ }^{7}$. My intention was to acknowledge Hawaii as ancestral home for ancient Polynesian voyagers, and Maori, by noticing they also have their own reinga, or leina too ${ }^{8}$. Te Rerenga Wairua, Cape Reinga, the northernmost tip of Aotearoa, New Zealand, is celebrated as a site of spiritual departure for the Maori. Tribal legends convey spirits of recently deceased, travel leylines wrapping across the country, to leap off the islands tip, the tail of the Fish of Maui ${ }^{9}$, down roots of an ancient pohutukawa tree at the side, heading out to the horizon, between the Pacific Ocean and the Tasman Sea towards far flung Hawaiiki ${ }^{10}$. In this place, these hemispheres

5 I have used my emails as a source material to reflect the nature of fragmentary knowledge and cultural revitalisation, a major part of the Whare Tapere as a research archive

6 Local Maori tribes hold various sources of story that relate to Cape Reinga or Rerenga Wairua as a spiritual highway. These leylines are echoed throughout the world, in places I have travelled such as Hawaii and New Mexico.

7 Part of the preparations for the Pacific Hall Grand Reopening Event in September 2013.

8 One such leina is the famous Kaena Point in Oahu

9 Maui is a Polynesian demi-god figure, who was credited with fishing up the North Island of New Zealand, known by its Maori name, Te Ika a Maui.

10 Hawaiiki is the oral tradition name for the ancestors former home, today the term could possibly refer to the Pacific Islands as well as the American continent 
of two waters, also known as wairua, or spirit, show convergences of both life and death. In an interview with Hawaii Public Radio I speak about daily livingness and how we honour spirit through dance:

We've become so segregated, and so separated in our daily livingness that we've forgotten that at the heart of it all, we just want to connect with each other. So yes I'm creating some dances but the bigger vision that I always have is opening up and creating processes that work for the people, that sustain and nourish their spirit, that give words or at least actions to their yearning,activating current protocols that they have been handed down. We don't need to walk away from those things, we need to actually just use them as an everyday touchstone where we all come together and go 'oh, whats important'? We've got a proverb back home, 'what is the most important thing?' And the answer is 'he tangata, he tangata, he tangata, it is the people, the people, the people'. The way we honour is to do. It means that we use our force, we use our power of our words, and we use our insistence to carve a space of recognition. 


\section{Photo: Alice Christophe}

Pictured: Dancers of the Te Reinga collaboration, Bishop

Museum, September 2013

\section{Mitimiti}

Born in Auckland, a cultural disassociation with my geographical identity, echoed as deep chasms within intergenerational urban drift ${ }^{11}$. I had an innate D.N.A knowing and willingly performed my desire of cultural spirit, though it also felt abstracted within the blackness, like a Ralph Hotere painting ${ }^{12}$. Returning to Mitimiti for the first time in 2011, part of a creative research expedition by Atamira Dance Company and with film crew in tow, I spent that weekend learning about place, forming foundations of choreographic research for the next years. Three years later, I finally looked back at the video footage, self-editing my first short 'docu-narrative' on iMovie ${ }^{13}$.

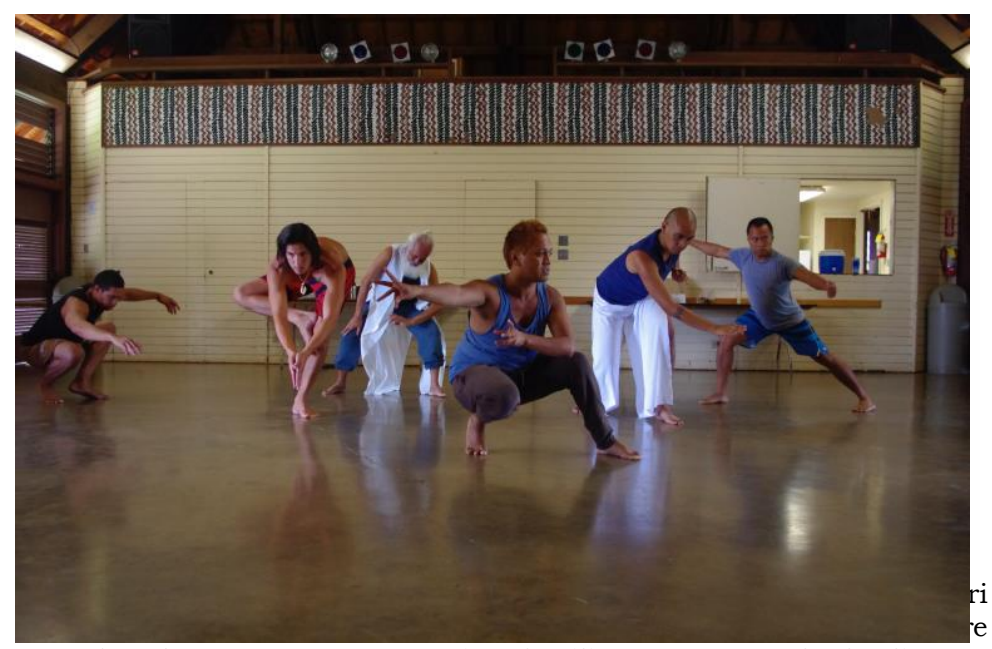

abundant resources to raise families consequently leading to cultural and geographic isolation

12 Ralph Hotere (1931-2013) is regarded as New Zealand's finest Maori contemporary painter known for his deep black lacquer paintings. He was born and is buried at Hione, the cemetery at Mitimiti.

13 Find the video at: https://youtu.be/o1m7qMc56HQ

Te Kaharoa, vol. 8, SPECIAL EdiTION, the Kowhiti Atarau collection, 2015, ISSN 1178-6035 
This biographical process collated as an emotional regathering, surrenders pain in exchange for new light. In 2015, my newest work emerged named 'Kopatapata'14, convergence of light and water, aimed to restore ancestral wear and tear, the anxiety of returning to my ancestors land still reads palpably in an email:

I was trying to go to sleep but a mosquito woke me up and besides that I have this unrequited melancholia - we say mokemoke - a feeling of longing, missing. I am feeling this the night before I leave Auckland and head to Mitimiti for the Marae D.I.Y ${ }^{15}$. That place just always does it to me. Asked how many times I've been, I had actually forgotten - I thought it was twice and then totally remembered a third. So it's my fourth time. I was thinking of each time I've been and how precious it's been. How like unwrapping a treasure, dusty keepsake, I'm very careful not to ruin it. I am wondering why I'm not happy, or joyous. I mean, I'm going to where I come from. And then it has started to dawn on me, that for whatever reason, my ancestors moved and left behind the wairua that was a part of who we were. So the reason I forgot how many times is because my spirit has gone back many times, drifting back and forth, through my memories, the video I made, the things I've written, the stories I've told, the dances I've made. And see all the taonga that I have generated in honour of something so important to me. I think about this, as I feel the discomfort, the unfamiliarity, the not having yet established belonging, the place of existence I myself have made peace with, and see my past, present, future views never ever erasing the truths and the way it was, is and can be. I just have to believe we can do this. We can heal. We can find peace. Be the peace. Offer the peace. I will always be driven by the pain and the love"

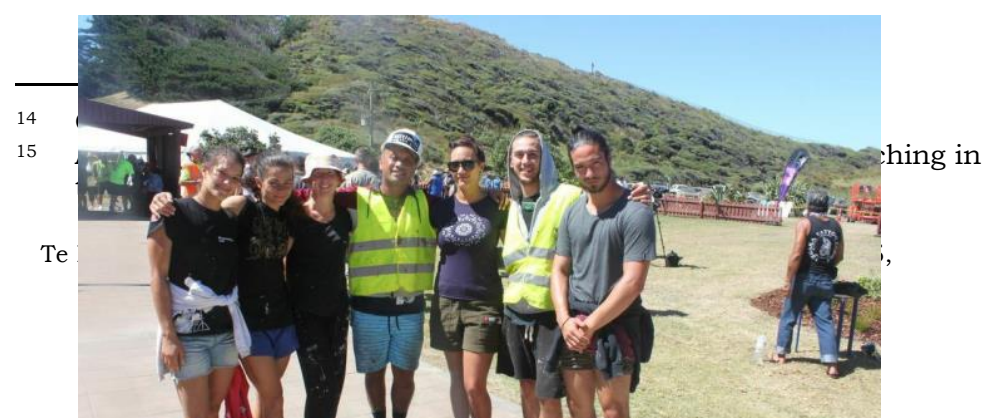


Photo: Robyn Kamira

Pictured: Dancers from Kopatapata by Atamira Dance

Company at Marae D.I.Y, Mitimiti

\section{California}

In 2014 I was invited to teach at the University of California Berkeley, as a guest choreographer for the Berkeley Dance Project ${ }^{16}$ after attending a 'luncheon' at the University of California, Berkeley, discussing 'Native issues' about a play 17 "Ishi - Last of the Yahi". At that meeting, I soon realised there was a tense encounter simmering between factious entities, departments, students, local Native communities, and meant that as an 'outsider' by default I functioned as a mediator of sorts. At the time I was able to support the negotiation of listening and talking, and by establishing protocols, I could later coordinate a series of exchanges between the University and the local tribal people, the Ohlone ${ }^{18}$, as well as indigenous and Native artists and practitioners. Co-creating a piece in 2014 with the dancers called 'Turangawaewae'19 was a similar process to "Te Reinga" shifting dramatically within an American context. My reflections illustrate the seismic relations and transformative effects of my time at Berkeley:

Berkeley has come and gone. It was a huge project - almost as cataclysmic as Te Reinga at times! I don't know why I always $s$ to uproot places and leave a wake, a trail of

16 Berkeley Dance Project: Intimate Distance was a triple bill curated by Lisa Wymore and presented at the Zellerbach Theatre in April 2014

17 Tria Andrews wrote a letter about the play that led to a greater community discussion and my subsequent connection to Berkeley. Here is her letter: http://nativeappropriations.com/2012/03/ishi-the-last-of-theyahi-a-uc-berkeley-production-that-perpetuates-gross-violencesagainst-native-peoples.html

18 One of the tribes is the Muwekma Ohlone found here: http://www.muwekma.org

19 Turangawaewae means 'Standing Place', the trailer is found here: https://youtu.be/CqzrlzEOOzc 
destruction and creation. Change, transformation, renewal definitely all recurring dreams/themes. I really worked hard on a few things. One being to make sure that the dancers had a really strong, profound sense of ownership of their cultures and their experience as people in the world. That I was able to weave together a multi dimensional dream scape that could reflect their archetypes, fears, frustrations and also hope for healing. It seemed to me that once the work was in the theatre they began to understand their korero more deeply and started to really play their characters and their catharsis out in real ways. In becoming far more aware of the humanity that is implicit in what I/we do, I learn how to encourage/nurture and really live it. I think the performances came alive because of the ceremony that happened. So many politics were involved in that. I liked Berkeley - its raw and radical and up and down, also still needing and waiting fora space of reclamation. I think the piece reflected it a lot. A living beast, a sense of burden and a hope for the future reconnection of mana whenua. I think it was all possible. I also think about what America keeps protecting itself from learning and wising up too. I mean there are Hawaiian protocols and indigenous protocols and seems like it doesn't draw from any of it. Which leads me to ask - why are they still occupied? 


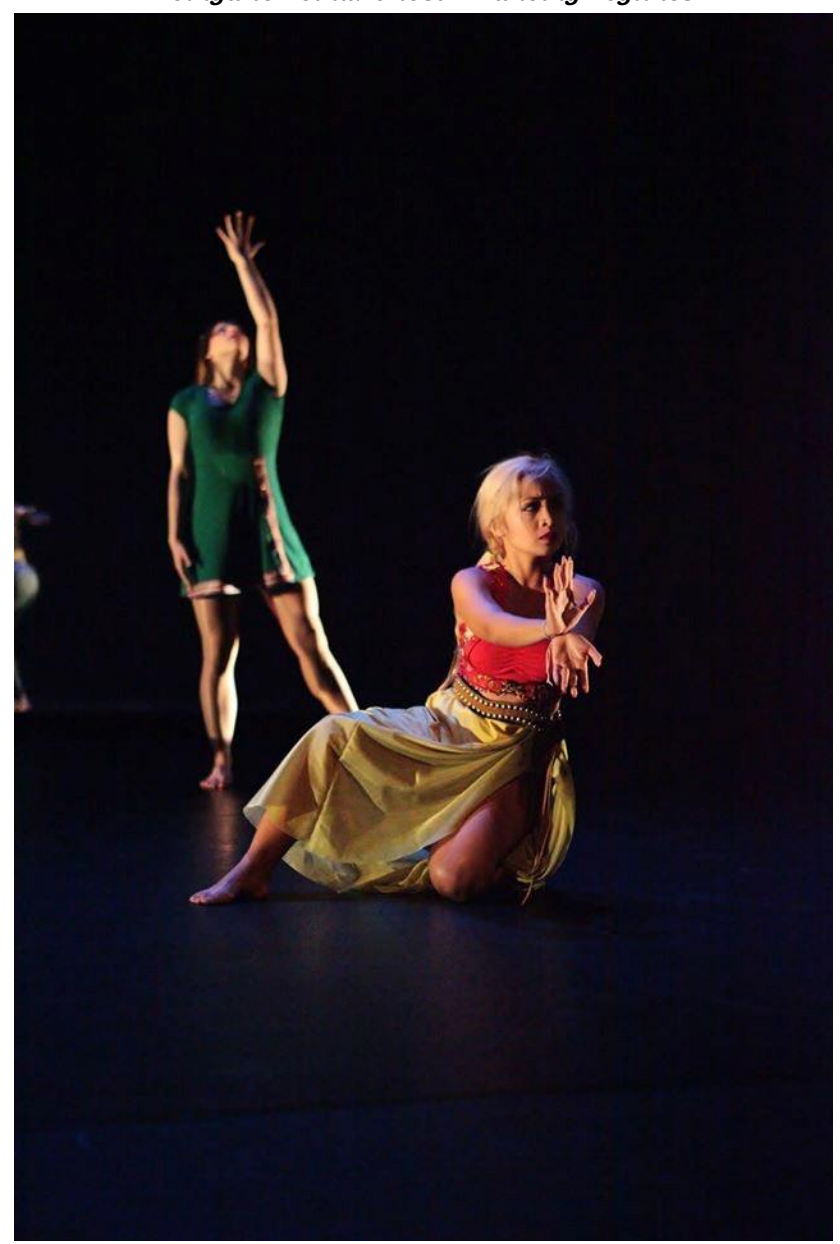

Photo: Yvonne Portra

Pictured: Dancers from Turangawaewae collaboration with the Berkeley Dance Project 2014

\section{California}

Last night we had a noho Marae at a karate dojo in Napa, and as I went to bed and saw my friends asleep in their 
blankets on the mats - I had a déjà vu to last year at the Bishop Museum. And so I checked my emails and discovered we were pretty much doing the noho Marae at Atherton Halau at almost the same date. A part of me kind of lifted in joy that I somehow ceremoniously manifested a cycle of connection and as well as that I reflected on the past, and my beautiful summer in Hawaii last year and all the water that has flowed, tides under bridges, moons behind cloud and risings of sun that has brought us to the now. I've certainly learnt alot and changed immensely since then, yet I carry the seeds and beauty of what we planted with Te Reinga and what continues to flourish in each of our lives. A diary entry captures a synchrocity:

I returned to the Museum, exactly a year after our momentous performance at the Grand Reopening of the Pacific Hall, to honour the passage of time. Over that year, we had all changed, people had come and gone, new friendships and relationships had sprouted or withered down, and the power of the time recalibrate to another place, another space.

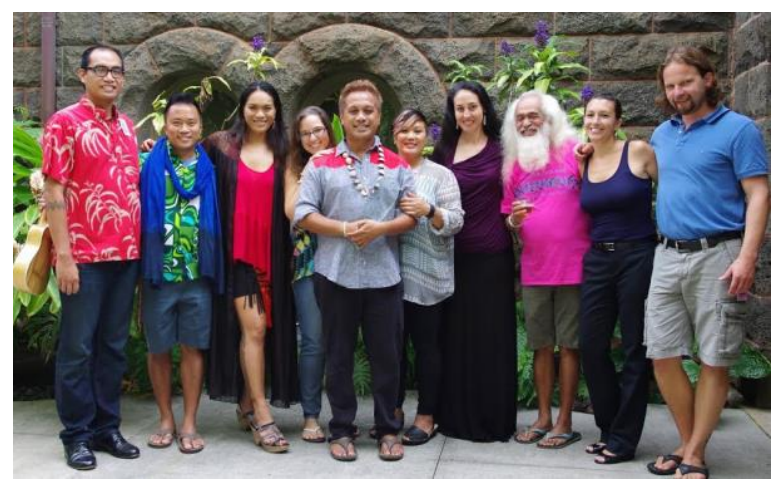

Photo: Alice Christophe

Pictured: Te Reinga collaborators and staff of the Bishop Museum 


\section{Te Reinga}

I will always be caressed by the golden sand of the Hokianga 20 and blown over the oceans as a spirit from $\mathrm{Te}$ Reinga. You cannot tell me this world that my ancestors gifted me Is not seen, felt and sensed in the stars, the crickets, the dark clouds I saw outside my house just before. I reach into the place of the unknown, to reveal the enduring potential beneath.

Tomorrow I will be in my land. I will be by bones I know. I will be meeting faces that are new. I will be doing things I've never done. I don't have a clue about construction! I will sleep in a marquee with my cousins and be under the quietest, blackest night in the country. Soon the world will know it through the Internet, so these literally are the last days of Te Po ${ }^{21}$. Maybe that's why I'm sad. Because ahead is only light. Of the new world, Te Ao Marama 22.

20 The harbour that was the first settled area by the original explorers, meaning "The Return"

21 Te Po, a cosmological reference to the Night in Maori creation stories

22 Te Ao Marama, a cosmological reference to the daylight and the World, in Maori creation stories 


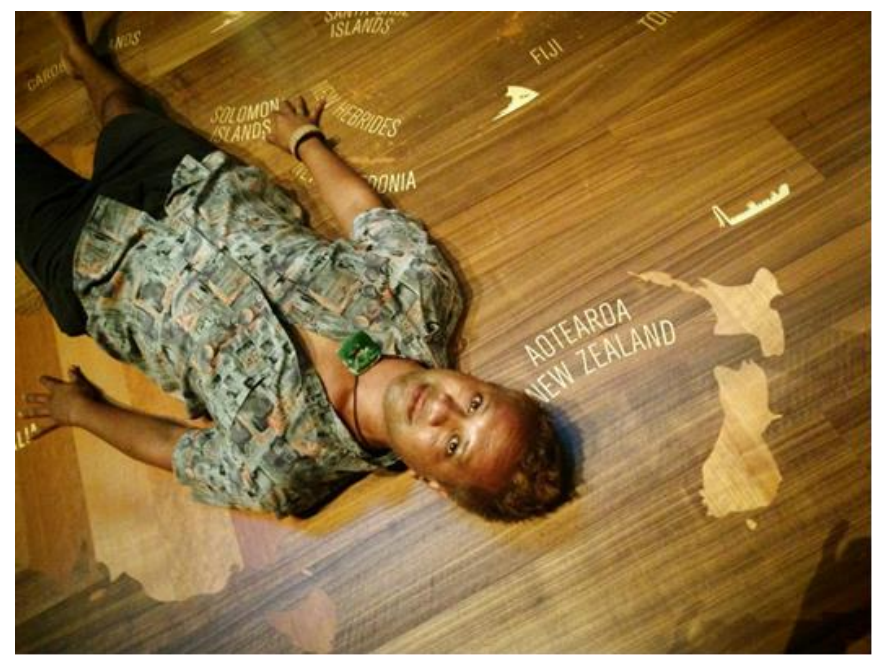

Photo: Jack Gray

Pictured: Jack Gray at the Pacific Hall, Bishop Museum, September 2013 